\title{
Práticas sustentáveis em unidades de alimentação e nutrição de hospitais públicos em Sergipe
}

\begin{abstract}
A sustentabilidade contempla uma lógica circular e inclusiva que visa ao equilíbrio dinâmico dos ecossistemas, a cooperação e a qualidade de vida das pessoas. É um termo que descreve uma nova forma de se compreender o desenvolvimento de uma sociedade por meio de políticas públicas que visem à sustentabilidade. Em âmbito hospitalar é possível e necessário que se estabeleçam práticas sustentáveis em Unidades de Alimentação e Nutrição (UANs). As UANs são unidades de trabalho que desempenham atividades relacionadas à alimentação e nutrição com estrutura administrativa simples, porém de funcionamento complexo. Elas desempenham importante papel em termos de economia e de saúde pública, uma vez que podem afetar o estado nutricional e o bem-estar da população por meio da qualidade do alimento que produzem. Uma UAN Hospitalar deve oferecer uma alimentação equilibrada, adequada à prescrição dietética de cada cliente/paciente, respeitando suas preferências, bem como as limitações impostas pelas doenças. Em consulta ao banco de dados do Cadastro Nacional dos Estabelecimentos de Saúde (CNES), a rede hospitalar pública do Estado de Sergipe é constituída por vinte e sete hospitais, sendo dois federais, doze estaduais e treze municipais. Desse modo, este artigo teve como objetivo analisar as práticas sustentáveis adotadas pelas Unidades de Alimentação e Nutrição dos hospitais públicos em Sergipe. Concluiu-se que as UANs dos hospitais públicos em Sergipe já adotam algumas práticas sustentáveis, mas necessitam de aprimoramento, sendo que o nutricionista é profissional essencial para implantar e conscientizar a equipe sobre a necessidade de preservar os recursos e reduzir o impacto ambiental provocado pela produção das refeições.
\end{abstract}

Palavras-chave: Práticas sustentáveis; Unidades de alimentação e nutrição; Hospitais públicos; Sergipe.

\section{Sustainable practices in food and nutrition units of public hospitals in Sergipe}

The Sustainability embracing a circular and inclusive logic that aims at the dynamic balance of ecosystems, cooperation and people's quality of life. It is a term that describes a new way of understanding the development of a society through public policies aimed at sustainability. In the hospital, it is possible and necessary to establish sustainable practices in food and nutrition units (UANs). The UANs are work units that perform activities related to food and nutrition with simple but complex administrative structure. UANs play an important role in terms of economy and public health, as they can affect the nutritional status and well-being of the population through the quality of the food they produce. A UAN Hospitalar should therefore offer a balanced diet, adequate to the dietary prescription of each client / patient, respecting their preferences, as well as the limitations imposed by the diseases. In consultation with the database of the National Register of Health Establishments (CNES), the public hospital network in the State of Sergipe consists of twenty-seven hospitals, two federal, twelve state and thirteen municipal. This article aimed to analyze the sustainable practices adopted by the Food and Nutrition Units of the public hospitals in Sergipe. It was concluded that the UANs of the public hospitals in Sergipe already adopt some sustainable practices, but they need improvement, being that the nutritionist is an essential professional to implant and make the team aware of the need to preserve the resources and reduce the environmental impact caused by the production of meals.

Keywords: Sustainable practices; Food and nutrition units; Public hospitals; Sergipe.

Topic: Desenvolvimento, Sustentabilidade e Meio Ambiente

Reviewed anonymously in the process of blind peer.
Received: 02/12/2018

Approved: $26 / 01 / 2019$
Ítalo Emanuel Rolemberg dos Santos Universidade Federal de Sergipe, Brasil http://lattes.cnpq.br/7836471533247839 italogrh@yahoo.com.br

Gregorio Guirado Faccioli (id

Universidade Federal de Sergipe, Brasil http://orcid.org/0000-0003-2666-3606 gregorioufs@gmail.com

Izabela Maria Montezano de Carvalho (iD Universidade Federal de Sergipe, Brasil http://lattes.cnpq.br/0103210968160524 http://orcid.org/0000-0002-1680-3137 i.montezano.c@gmail.com

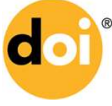

DOI: 10.6008/CBPC2179-6858.2019.001.0016
Alane Regina Rodrigues dos Santos Universidade Federal de Sergipe, Brasil http://lattes.cnpq.br/1862361381380273 alane-rs@hotmail.com

Carina Angélica dos Santos

Universidade Federal de Sergipe, Brasil http://lattes.cnpq.br/0958272775522614 profcarina@yahoo.com.br
Referencing this:

SANTOS, Í. E. R.; FACCIOLI, G. G.; CARVALHO, I. M. M.; SANTOS, A. R. R.; SANTOS, C. A.. Práticas sustentáveis em unidades de alimentação e nutrição de hospitais públicos em Sergipe. Revista Ibero Americana de Ciências Ambientais, v.10, n.1, p.195-210, 2019. DOI: http://doi.org/10.6008/CBPC2179-6858.2019.001.0016 


\section{INTRODUÇÃO}

A temática da alimentação é, sem dúvida, uma das mais complexas e relevantes para a vida dos seres vivos, uma vez que as questões envolvendo nutrição e seus determinantes biológicos envolvem aspectos ambientais, culturais e psicológicos, não estando ligadas apenas à sobrevivência do indivíduo e da espécie, mas também a relações sociais, qualidade de vida e produtividade.

A alimentação é percebida como uma das necessidades cuja satisfação influencia no bem-estar social. Seguindo esta conceituação de dependência entre alimentação e bem-estar humano, considera-se que a satisfação física acontece em interação com outros aspectos, como integração psicológica, desenvolvimento de faculdades mentais e nível de aprendizado. Dessa forma, oferecer uma alimentação saudável, sob uma perspectiva quanti e qualitativa, contribui para o crescimento, desenvolvimento e manutenção do indivíduo.

O mercado de alimentação contempla refeições feitas em casa ou fora dela, ou seja, é representado pelos estabelecimentos envolvidos com a produção, distribuição e processamento de alimentos para qualquer tipo de coletividade. As refeições realizadas fora de casa são denominadas de alimentação coletiva e alimentação comercial, a exemplo das servidas em empresas, escolas, hospitais, asilos, prisões, restaurantes, entre outras.

Nas duas últimas décadas, empresas e instituições passaram por mudanças radicais nos modelos de gestão. Palavras como qualidade, produtividade, custos e satisfação do cliente tomaram conta do mercado, tornando-se fatores básicos para a sobrevivência organizacional. Essas mudanças se intensificaram e exigiram que o mercado de alimentação coletiva acompanhasse esta tendência por meio da atualização de conhecimentos técnicos e administrativos no gerenciamento de Serviços de Alimentação e Nutrição (SAN), também chamados, mais recentemente, de Unidades de Alimentação e Nutrição (UAN).

Em se tratando de empresa, oferecer uma alimentação balanceada, em conformidade com as recomendações nutricionais, é condição fundamental para o alcance de objetivos desejáveis, dentre eles: aumento da produtividade e da qualidade do produto ou serviço, redução de acidentes de trabalho, diminuição do absenteísmo e rotatividade de mão-de-obra. De modo mais abrangente, poder-se-ia afirmar que oferecer uma alimentação cientificamente equilibrada constitui um instrumento de maior interação funcionário/empresa.

A UAN pode ser considerada a unidade ou setor de trabalho de uma empresa que desenvolve atividades relacionadas à alimentação e nutrição ou, ainda, pode ser considerada um subsistema integrante do sistema maior, desempenhando uma função útil à sua existência (TEIXEIRA et al., 2004), isto é, as UANs podem desempenhar atividades-fim ou meio. No primeiro caso, como órgãos fins, estão as UANs de hospitais e centros de saúde, que colaboram diretamente para o alcance do objetivo principal da entidade, uma vez que sua atuação interfere na prevenção, manutenção e/ou recuperação da população que atende. No segundo caso, podem ser citadas as UANs de indústrias, escolas e universidades, creches, asilos e abrigos, as quais desenvolvem atividades visando a um melhor desempenho na população atendida além da prevenção 
e manutenção do estado nutricional de seus clientes, contribuindo para que sejam realizadas, da melhor forma possível, as atividades fins da instituição.

Dada a importância das UANs para coletividades, tenham elas como público-alvo pessoas sadias ou adoentadas, não se pode desconsiderar a importância da realização de atividades sustentáveis. $\mathrm{O}$ tema sustentabilidade está presente em todos os núcleos da sociedade. Por isso, identificar soluções e adotar medidas que minimizem os impactos ambientais, sociais e econômicos nas atividades diárias é imprescindível aos diferentes segmentos econômicos e áreas de atuação, desde a indústria até o terceiro setor. No âmbito da alimentação coletiva, esta postura tem como parâmetro o conceito de Green Kitchen ou, literalmente, Cozinha Verde (LASUPRE, 2016).

No Brasil, o conceito de Cozinha Verde não está amplamente disseminado, mas é possível classificar alguns estabelecimentos deste modo, haja vista que, para ser sustentável, um ambiente que atue na área de refeições coletivas pode adotar todo um conjunto de ações ou parte dele. Nesse sentido, um ambiente profissional destinado ao preparo de alimentos deve seguir as regras básicas de qualquer outro setor: Reduzir (economizar insumos), Reutilizar (aproveitar melhor os alimentos) e Reciclar (materiais de descarte ou lixo orgânico). Vale destacar que, mesmo que a prioridade seja minimizar os impactos ambientais na cozinha, é preciso respeitar uma norma primordial: a segurança alimentar (LASUPRE, 2016).

Em perspectiva acadêmica foram encontrados poucos trabalhos relacionados à sustentabilidade na produção de refeições. Entre eles, o tema mais abordado foi a quantificação do volume de resíduos orgânicos produzidos em UANs. Em se tratando de Gestão Sustentável em UANs de hospitais públicos, não foi encontrado, especificamente, nenhum estudo, aspecto este que corrobora para a relevância da Tese ora proposta.

Dessa forma, considerando os aspectos apresentados, justifica-se o presente estudo pela possibilidade de conhecer práticas sustentáveis adotadas nas UANs dos hospitais públicos de Sergipe, possibilidade está ratificada por Veiros et al. (2010) ao afirmar que "a sustentabilidade é um assunto importante, inclusive para o nutricionista, por ser um cidadão consciente de seus deveres e de suas possibilidades de contribuir com a sociedade e o meio ambiente" e pelo fato de que os profissionais de alimentação e nutrição estão demonstrando uma maior preocupação com os impactos ambientais gerados pelas UANs ao ambiente, carecendo da busca de alternativas consideradas mais sustentáveis que também poderão servir de subsídio para uma dieta mais saudável e sustentável. Há que se mencionar também a relevância do tema para gestores públicos, uma vez que a temática apresentada reveste-se de importância pela possibilidade de subsidiar práticas de gestão das despesas públicas que venham trazer eficiência, eficácia e efetividade no controle dessas atividades.

\section{REVISÃO TEÓRICA}

\section{Desenvolvimento Sustentável}


O desenvolvimento sustentável é um conceito atual que, somente nas últimas décadas, tem sido extremamente considerado e estimado, principalmente, após a reunião Eco-92, no Rio de Janeiro, e a criação da Agenda 21. A noção de desenvolvimento sustentável inclui todos os aspectos que estão embutidos no conceito de desenvolvimento econômico, mas carrega consigo outras ideias. Considerando que o desenvolvimento sustentável é uma maneira de agir no presente pensando no futuro, e que isso requer a conscientização da população mundial, torna-se imprescindível que cada indivíduo tenha noção da importância de suas atitudes que, somadas às dos outros, representam a garantia de um futuro digno tanto nas questões sociais quanto nas questões ambientais.

Em consequência dos problemas ambientais enfrentados resultantes do desenvolvimento, pensouse na criação de um novo modelo desenvolvimentista calcado numa base social, econômica, cultural e ambiental mais sustentável, tornando-se um desafio a construção desse novo modelo carregado de princípios sustentáveis. Cavalcanti (2003) menciona que atualmente existem dois paradigmas principais de sustentabilidade: o desenvolvimento segundo uma visão econômica, classificando a natureza como um bem de capital, ou seja, a sustentabilidade como algo ambiental; e o desenvolvimento que tenta romper com a dominação do discurso econômico, ou seja, a sustentabilidade como algo ético.

A concepção que coloca a natureza como bem econômico tem a pretensão de condicionar a produção nos limites da capacidade de suporte dos recursos naturais e, portanto, não prevê o que pode resultar no campo sociopolítico. Porém, esses limites resultariam diretamente na obtenção de lucros e, sendo assim, alguém teria que assumir responsabilidades sobre isto. Tendo em vista a lógica capitalista, a diminuição de lucros não é algo que os países queiram acatar (CAVALCANTI, 2003).

Já a segunda concepção propõe um deslocamento da racionalidade econômica para o campo da ética. Há uma maior preocupação com a vida humana e com a manutenção de sua qualidade. No entanto, colocá-la em prática seria um desafio, uma vez que se faz necessário equilibrá-la com o economicamente eficiente e produtivo. Dado o exposto, destaca-se a necessidade de um elevado grau de educação populacional para compreender que o ecossistema não é capaz de sustentar de maneira infinita o nível de atividade econômica e de consumo de matéria-prima (BELLEN, 2004).

Os debates mais importantes sobre a questão ambiental iniciaram na década de setenta do século XX. O livro Primavera Silenciosa, lançado em 1962 por Rachel Carson, representou um marco para a história do ambientalismo mundial ao relatar os efeitos contrários da má utilização dos pesticidas e inseticidas químicos sintéticos. Naquele período, os principais problemas ambientais eram o crescimento populacional, o desenvolvimento industrial e a corrida armamentista por testes nucleares. As mais diversas conferências internacionais elaboraram documentos visando esclarecer o desenvolvimento sustentável e estabelecer normas voltadas a alterar os padrões de produção e consumo adotados na atualidade (COSTA, 2011).

Em 1958 foi estabelecida no Brasil a Fundação Brasileira para a Conservação da Natureza, segundo a qual a inclusão de preocupações mais radicalmente sociais nas questões ambientalistas recentes não desqualificava a preocupação com a defesa estrita da biodiversidade contra a ameaça mais séria que sofria, a saber: a expansão das atividades produtivas humanas (FRANCO et al., 2009). A década de 60 foi marcada 
por movimentos que criticavam o modo de vida e não apenas a forma de produzir das indústrias. Os padrões de produção e consumo que marcam os limites do crescimento econômico, caracterizado pelo modelo de desenvolvimento da razão tecnológica sobre a organização da natureza, foram questionados (BERNARDES et al., 2003).

Costa (2011) ressalta que, na busca de reduzir a crise ambiental e de tornar o crescimento e o desenvolvimento econômico viável e sustentável, o homem passou a se preocupar com os impactos de suas atividades sobre o meio ambiente. O marco dessa mudança foi a Conferência das Nações Unidas sobre o Meio Ambiente Humano, celebrada em Estocolmo, em 1972, na qual foi oficializada a preocupação global sobre os problemas ambientais. Scander Neto (2006) e Costa (2011) afirmam que a Conferência das Nações Unidas sobre o Meio Ambiente Humano representou um importante momento para a redefinição do sentido do desenvolvimento e sua relação com o meio ambiente.

Em 1972 aconteceu o Dia da Terra, maior manifestação ambientalista da história, ocasião na qual se discutiu a importância de integrar o meio ambiente às estratégias de desenvolvimento (CAMARGO, 2007). Em 1973 o conceito de Ecodesenvolvimento ganhou destaque, uma vez que trouxe como proposta a concepção de um sistema social capaz de garantir emprego, segurança social e respeito à diversidade cultural, destacando a relevância de programas de educação que valorizem essas dimensões (OLIVEIRA, 2007).

Para Souza et al. (2006), o ecodesenvolvimento trata-se de um modelo ainda embrionário, pois não existem experiências empíricas e criteriosas, fazendo com que ele seja contestado e precise de uma maior qualificação. Surge, assim, a proposta de sustentabilidade, partindo da ideia de que o conceito de ecodesenvolvimento se baseava na justiça social, eficiência econômica, condicionalidade ecológica e respeito à diversidade cultural.

$\mathrm{Na}$ tentativa de explicar a relação entre crescimento e meio ambiente, duas correntes ganharam espaço na ciência econômica: a Economia Ambiental, segundo a qual a solução encontrava-se na ampliação do mercado e valoração monetária dos recursos ambientais, além de supor que as externalidades que estão fora do mercado podem receber uma valoração monetária suficiente; e a Economia Ecológica, a qual questionava os fundamentos da crise ambiental e afirmava que a base dos problemas ambientais está na busca do crescimento econômico como um fim em si mesmo (PIRES, 2014).

Bossel (1999) afirma que desenvolvimento sustentável compreende a atividade humana voltada a alimentar e perpetuar o histórico cumprimento de toda a continuidade da vida na Terra. Nesse sentido, Bellen (2004) defende que o conceito sobre Desenvolvimento Sustentável divulgado na ECO-92 alcançou destaque tornando-se um dos termos mais utilizados para se definir um novo modelo de desenvolvimento, no entanto faltou uma discussão crítica e consistente sobre seu significado.

Para Lima et al. (2007), o Desenvolvimento Sustentável se preocupa com o crescimento, com a qualidade do crescimento com o objetivo de atender às necessidades humanas, atingir níveis sustentáveis de pobreza, conservar e preservar os recursos naturais e adaptar a tecnologia evitando impactos ao meio ambiente, incorporando economia e meio ambiente na tomada de decisão. 
Para minimizar os impactos ambientais decorrentes das atividades humanas elaborou-se o Protocolo de Kyoto, o qual se voltou ao comprometimento das nações na redução, entre 2008 e 2012, da emissão dos gases poluentes que causam o efeito estufa. Foi consagrado o princípio do 'poluidor pagador', segundo o qual, embora a poluição seja um problema ambiental global, é dos países industrializados a responsabilidade de evitar que se agrave. Rodrigues (2009) afirma que o referido Protocolo, por meio dos Mecanismos de Desenvolvimento Limpo, intenciona promover a criação de fundos monetários voltados à área ambiental para implementar projetos em setores energéticos nos países em desenvolvimento; mitigar a crise econômico-ecológica; e modificar a matriz energética mundial (JURAS, 2007).

Feitosa (2016) escreve sobre a adoção de uma sustentabilidade ecológica sugerida por Leff (2010) e concebida enquanto critério de reconstrução dos parâmetros de desenvolvimento humano que possui como pilares a integração dos valores e potenciais da natureza, as externalidades sociais, os saberes subjugados e a complexidade das relações que se estabelecem entre os indivíduos e o ambiente. Essa nova racionalidade ecológica deve ser pautada na ética ambiental, que vincula a conservação da diversidade biológica do planeta ao respeito à heterogeneidade ética e cultural da espécie humana. Deve ser priorizada a conservação da própria cultura e tradições, bem como os princípios da gestão participativa para o manejo de seus recursos de onde as comunidades derivam suas formas culturais de bem-estar e a satisfação de suas necessidades (LEFF, 2010).

\section{Unidades de Alimentação e Nutrição}

As UANs são unidades de trabalho que desempenham atividades relacionadas à alimentação e nutrição com estrutura administrativa simples, porém de funcionamento complexo (VEIROS, 2002). Essas unidades pertencem ao setor de alimentação coletiva, cuja finalidade é administrar a produção de refeições nutricionalmente equilibradas, com adequado padrão higiênico-sanitário para consumo fora do lar, visando a contribuir na manutenção ou recuperação da saúde de coletividades e, ainda, auxiliar no desenvolvimento de hábitos alimentares saudáveis (COLARES et al., 2007).

Essas unidades desempenham importante papel em termos de economia e de saúde pública, uma vez que podem afetar o estado nutricional e o bem-estar da população por meio da qualidade do alimento que produzem. Por isso, profissionais que atuam nelas devem se preocupar não somente com a qualidade do alimento pronto, mas também com fatores que possam interferir nesta qualidade, desde a escolha e o fornecimento de matéria-prima e equipamentos, passando pelo armazenamento e finalizando com a produção e consumo (AGUIAR, 2003).

Segundo Teixeira et al. (2004), o êxito no funcionamento de uma UAN está na dependência da definição clara de seus objetivos, sua estrutura administrativa, suas instalações físicas e recursos humanos e, sobretudo, da normatização de todas as operações desenvolvidas, as quais devem estar respaldadas nos cinco elementos do processo administrativo básico: previsão, organização, comando, coordenação e controle. Por isso, necessita não somente de pessoal qualificado para garantir a produção de refeições seguras, equilibradas e saborosas, mas também de infraestrutura e recursos físicos adequados provenientes 
de fontes confiáveis e seguras para que os custos de serviços com alimentação sejam reduzidos (AGUIAR, 2003).

Compete ao nutricionista atuante em UANs responsabilizar-se pelo planejamento, organização, supervisão, controle de produção, minimização de desperdícios e melhoria da qualidade dos alimentos, ou seja, uma atribuição desse profissional refere-se à adoção de estratégias de gerenciamento ambiental para minimizar impactos ambientais e maximizar a produtividade. Portanto, uma das preocupações que se deve ter nas UANs é com o meio ambiente, pois nessas unidades o processo de transformação da matéria-prima gera grande quantidade de resíduos, tornando-se importante adotar práticas de trabalho que respeitem o meio ambiente e que sejam práticas sustentáveis (SOUZA, 2008).

Culturalmente, a alimentação hospitalar é referenciada como insossa, mal preparada, sem gosto, fria, servida cedo e restritiva (SOUSA et al., 2011). Considerando-se que o ato de comer não está relacionado apenas à nutrição, mas abrange necessidades fisiobiológicas, sobrevivência, sociabilidade, afetividade, saberes, preferências, gostos, aprendizagens, obrigações, prazer, além de implicar também em um valor simbólico, torna-se complexo e exigindo outro tipo de abordagem quando se faz referência a gerenciar uma UAN (GALISA, 2014).

Em se tratando de UAN Hospitalar, deve-se oferecer uma alimentação equilibrada, adequada à prescrição dietética de cada cliente/paciente, respeitando suas preferências, bem como as limitações impostas pelas doenças, além de se adequar à disponibilidade financeira e de pessoal do serviço, já que o planejamento inadequado da UAN pode ocasionar superprodução de alimentos e, consequentemente, desperdício (NONINO-BORGES et al., 2006).

Os alimentos passam por diversas etapas durante o processo de elaboração das refeições: recebimento, estocagem à temperatura ambiente, estocagem a frio, pré-preparo, preparo, espera para distribuição, distribuição e descarte. Por conta disso, ficam evidentes os perigos e riscos quanto à segurança higiênico-sanitária que são acrescentados ou reduzidos ao preparo da refeição, a depender da maneira como são armazenados e manipulados os alimentos. Por conseguinte, os serviços de alimentação e nutrição hospitalares devem possuir controle sobre todas as etapas do processo de produção que iniciam no contato com os fornecedores e passa pelas etapas de limpeza, acondicionamento, pré-preparo, preparo e distribuição das refeições. Torna-se necessário, ainda, pesquisar frequentemente a satisfação dos pacientes servindo assim como indicador de bom serviço da UAN (GALISA, 2014).

Por isso é importante refletir não somente sobre o ambiente, na perspectiva da sustentabilidade, como também sobre a importância do profissional tecnicamente responsável pelas atividades do setor de Nutrição e Dietética (SND), já que o número crescente de UANs para atender a demanda da sociedade atual referente à alimentação fora de casa exige uma postura ambiental, profissional e ecológica que preserve recursos naturais e minimize danos ambientais (COSTELLO et al., 2009; FRIEL et al., 2009).

Além disso, a produção de resíduos sólidos provenientes dessas unidades desde a produção até a distribuição da refeição constitui-se outro fator preocupante, sobretudo por impactar diretamente na qualidade de vida da sociedade, desencadeando a necessidade de interação entre a gestão de resíduos e as 
rotinas operacionais dos serviços de alimentação. Portanto, o gerenciamento ambiental no segmento de alimentação institucional deve ser implementado em todos os setores do serviço, ou seja, no recebimento, pré-preparo, cocção e distribuição das refeições, haja vista que cada setor possui suas peculiaridades, sendo responsável pela geração de diferentes tipos e quantidades de resíduos, tornando necessário caracterizar a geração de resíduos em cada setor da UAN (ABREU et al., 2011).

\section{METODOLOGIA}

O estudo foi realizado nas dependências das UANs dos hospitais públicos do Estado de Sergipe. Segundo dados de 2018 do Cadastro Nacional dos Estabelecimentos de Saúde (CNES), a rede hospitalar pública em Sergipe possui vinte e sete hospitais, sendo dois federais, doze estaduais e treze municipais. Todavia, integraram o presente estudo apenas os federais e os estaduais, pois neles havia obrigatoriedade da presença do Responsável Técnico (Nutricionista) na UAN, totalizando quatorze estabelecimentos hospitalares participantes da pesquisa.

A pesquisa, quanto aos objetivos, foi do tipo exploratória, descritiva e explicativa. A pesquisa exploratória proporciona maior familiaridade com o problema, visando a esclarecer, desenvolver e modificar conceitos e ideias e proporcionar visão geral acerca de determinado fato. Já a descritiva intenciona descrever as características de um dado fenômeno. Por fim, a pesquisa explicativa permite identificar fatores que determinam ou contribuem para a ocorrência de um fato, visando ao aprofundamento do conhecimento da realidade (GIL, 2010).

Quanto aos procedimentos, a pesquisa foi bibliográfica, realizada a partir do levantamento de referências teóricas analisadas e publicadas cientificamente acerca da temática sustentabilidade em UANs. Realizou-se também pesquisa de campo, visando à observação de fatos e fenômenos ocorridos no cotidiano da prática laboral nas UANs, à coleta de dados referentes aos mesmos (GIL, 2010).

Para identificar as práticas sustentáveis adotadas pelas UANs criou-se um questionário subdividido em secções, o qual foi respondido pelo Responsável Técnico da UAN (Nutricionista) durante horário regular de trabalho na Unidade, mediante assinatura do Termo de Consentimento Livre e Esclarecido. O questionário permitiu levantar informações sobre: características gerais das UANs (cidade de localização, quantidade de refeições produzidas/dia, forma de distribuição das refeições, política de gerenciamento, frequência de funcionamento e número de funcionários); características gerais dos equipamentos e instalações das UANs (equipamentos, torneiras, iluminação e ventilação); características gerais das práticas de sustentabilidade ambiental adotadas (gestão ambiental, treinamento sobre práticas sustentáveis ambientalmente, recursos hídricos e energéticos e gerenciamento dos resíduos); e práticas sustentáveis adotadas em cada etapa de produção das refeições (planejamento de cardápios, aquisição, recebimento, armazenamento, pré-preparo, preparo e distribuição).

Ao término do levantamento das informações procedeu-se com a tabulação, análise e interpretação dos dados, embasando-se numa fundamentação teórica consistente, objetivando compreender e explicar o 
problema pesquisado. Os dados coletados foram tratados estatisticamente por meio de técnicas de estatística descritiva, as quais permitiram descrevê-los e apresentá-los conforme secção seguinte.

\section{RESULTADOS E DISCUSSÃO}

As UANs dos hospitais públicos em Sergipe se caracterizam por funcionarem as $24 \mathrm{~h}$ durante toda a semana. O gerenciamento das refeições acontece por meio de empresas terceirizadas que distribuem as refeições, de maneira porcionada, pelos respectivos funcionários das unidades. Verificou-se que todas as unidades fazem uso de alimentos regionais durante a elaboração do cardápio e preparo das refeições e consideram a sazonalidade dos alimentos na elaboração do cardápio. Em se tratando do modo de recebimento de vegetais e frutas, os mesmos são recebidos na forma in natura na totalidade das UANs.

Com relação à localização, 29\% das UANs encontram-se em Aracaju, capital do Estado de Sergipe, apresentando maior demanda de comensais. Em relação aos $71 \%$ restantes, observou-se que as unidades estão igualmente localizadas entre os municípios sergipanos que apresentam os maiores índices populacionais, isto é, Nossa Senhora do Socorro, Lagarto e Itabaiana. Vale mencionar que, em se tratando do ente público responsável pela administração das unidades hospitalares, somente 01 UAN (7\%) é administrada pela União, estando as demais (93\%) sob responsabilidade do poder público estadual. No que concerne ao tempo de atividade profissional dos responsáveis pela gestão das UANs, a maior parte (50\%) possui mais de três anos de atuação. $29 \%$ possuem até dois anos de atividades e uma minoria (21\%) apresenta entre dois e três anos de serviços prestados em UANs.

Quando analisada a quantidade de refeições diárias servidas, percebeu-se que o Hospital de Urgências de Sergipe (HUSE), inclusive pelo porte, é o que mais serve refeições diariamente. Esse estabelecimento hospitalar concentra quase metade das refeições diárias servidas no geral pelos hospitais, uma vez que das 8180 refeições preparadas pelas UANs dos hospitais estaduais, isoladamente essa unidade concentra o quantitativo de 4.000 refeições/dia, seguida pela Maternidade Nossa Senhora de Lourdes (MNSL), segundo maior estabelecimento público hospitalar no estado, a qual serve uma média de 1000 refeições/dia. Essas UANs se sobressaem por ser o HUSE o maior hospital público do estado de Sergipe, para onde são direcionados os pacientes em situação de alta gravidade, e a Maternidade Nossa Senhora de Lourdes ser a única que atende pacientes em situação de gravidez de risco, ficando evidente que há relação direta entre o número de refeições servidas e o número de leitos hospitalares cadastrados pelo Ministério da Saúde para os estabelecimentos hospitalares do Estado de Sergipe.

Os dados apresentados no Gráfico 1 demonstram que a maioria das UANs (64\%) realiza o descongelamento por meio da refrigeração, enquanto outras $29 \%$ descongelam expondo os alimentos à temperatura ambiente e 7\% utilizam água corrente para auxiliar no descongelamento. Opostamente ao resultado prioritário aqui encontrado, no estudo de Pagotto et al. (2018), 50,7\% dos participantes relataram descongelar alimentos em temperatura ambiente. $\mathrm{O}$ descongelamento inadequado favorece a multiplicação microbiana nos alimentos e, consequentemente, contribui para a ocorrência de toxinfecções alimentares. Resultado semelhante foi encontrado no estudo de Cunha et al. (2014), sendo a mais inadequada prática 
citada pelos manipuladores, na qual 34,6\% dos entrevistados relataram sempre executar o descongelamento desta forma.

\section{Procedimento de Descongelamento de Alimentos}

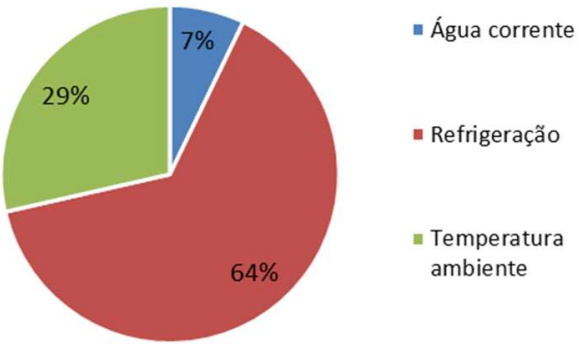

Gráfico 1: Procedimentos para Descongelamento de Alimentos.

Para preparar o quantitativo expressivo de alimentação diária, o número de colaboradores nas unidades não foge ao número de refeições produzidas, ratificando a relação entre número de leitos hospitalares, quantidade de refeições servidas, número de empregados para preparar as refeições e monitoramento do desperdício de alimentos. Em relação a este aspecto, pouco mais de $71 \%$ das UANs monitoram os desperdícios alimentares diários. Dessas, $29 \%$ monitoram por meio do resto ingesta e outras 71\% empregam, concomitantemente, o resto ingesta e o peso de sobra limpa, conforme gráfico 2.

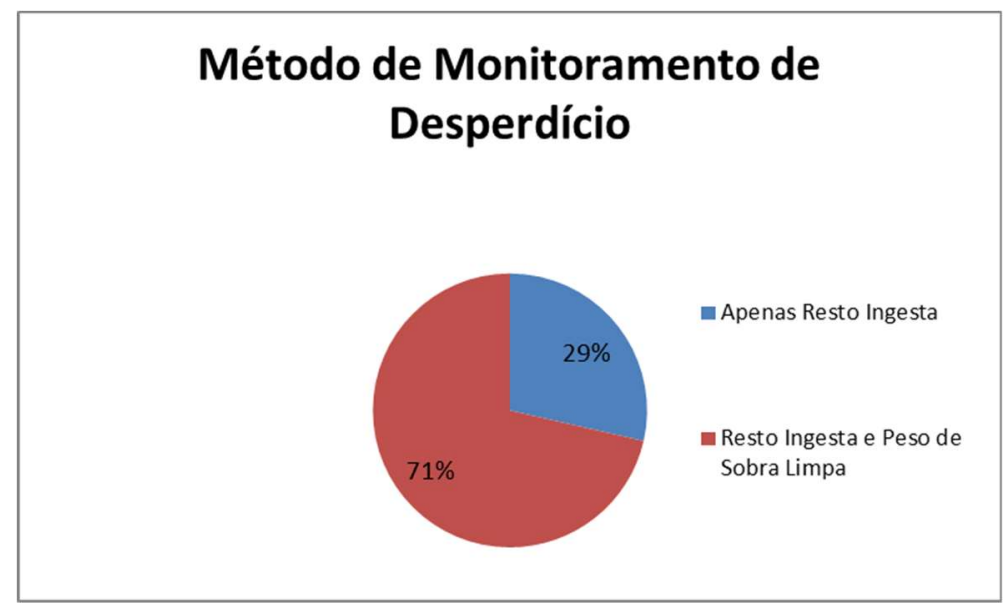

Gráfico 2: Método de Monitoramento de Desperdício.

O método da sobra limpa consiste na pesagem do alimento que foi preparado, mas não distribuído, devendo ficar sob refrigeração e monitoramento de tempo/temperatura. Já o resto ingesta adota a pesagem dos alimentos servidos e não consumidos (sobras nos pratos e bandejas), mas que os consumidores descartam no cesto de lixo (RABELO et al., 2016). O resto deve ser avaliado e compreendido não somente do ponto de vista econômico, como também, da falta de integração com o cliente (VAZ, 2006), já que evidencia a necessidade de fazer campanhas educacionais direcionadas aos comensais para controlá-lo e diminuir o desperdício. O referido autor ainda cita que o tamanho do prato ou a quantidade e/ou tamanho das vasilhas utilizadas pode induzir os clientes a se servirem de uma quantidade maior que a possibilidade de consumo 
e, consequentemente, gerar maior quantidade de restos. São aceitáveis como percentual de resto ingesta taxas entre 2 e $5 \%$ da quantidade servida ou de 15 a $45 \mathrm{~g}$ por pessoa.

Considerando que há geração de resíduos sólidos na produção e consumo de refeições nas unidades, deve-se priorizar, de maneira sequencial, segundo a Política Nacional de Resíduos Sólidos, a não geração, redução, reutilização e reciclagem, bem como disposição final ambientalmente adequada dos rejeitos (BRASIL, 2010; SRASBURGS et al., 2012). Por isso, as UANs devem adotar mecanismos para reduzir o impacto ambiental e conservar os recursos naturais (ABREU et al., 2009; FRIEL et al., 2009; LEAL, 2010; MARTINS, 2014). Conforme o Gráfico 3, 93\% das UANs destinam as sobras dos alimentos para o lixo, enquanto $7 \%$ destinam para servir de alimentos para os animais.

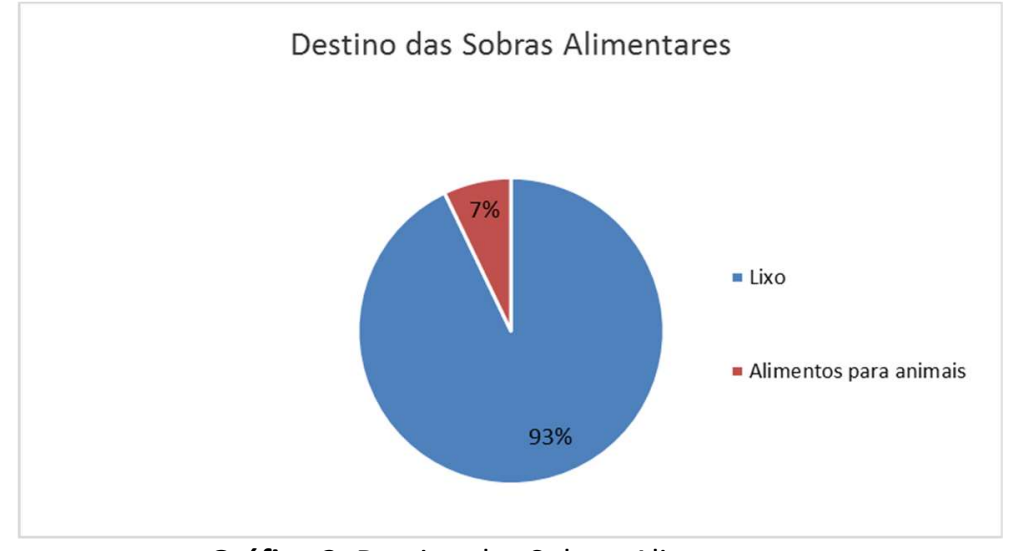

Gráfico 3: Destino das Sobras Alimentares.

Dados da pesquisa revelaram a utilização de freezer, geladeira e liquidificador nas 14 UANs, exigindose dos gestores das unidades preocupação com a manutenção de tais aparelhos, a qual é realizada na maioria das unidades (57\%) apenas de forma corretiva, em detrimento da minoria (43\%) que faz a corretiva e a preventiva.

Para a preparação das mais de 5.000 refeições/diária, uma informação levantada na pesquisa e que demonstra preocupação com a questão ambiental, sobretudo com o uso racional de água, foi a forma de acionamento das torneiras. A maioria das unidades (93\%) tem acionamento mecânico nas torneiras e a minoria (7\%) só possui o manual.

Já em relação ao uso de fonte de energia alternativa nas UANs hospitalares, 36\% das unidades não fazem uso de nenhuma fonte, enquanto que, dentre as que a usam, a maioria (50\%) só usa a fonte elétrica e $36 \%$ usam as fontes elétrica e o gás, conforme o Gráfico 4. Em se tratando da adoção de programas para evitar desperdício de água e energia, 93\% das UANs não possuem nenhum programa desse tipo e apenas 7\% possuem programa voltado exclusivamente para o uso racional da água, conforme apresentado no Gráfico 5.

Os dados apresentados no Gráfico acima demonstram que poucas UANs podem ser consideradas sustentáveis, pois elas abrangeriam serviços de alimentação capazes de produzir cardápios e ofertar alimentos saudáveis, produzidos por meio de práticas agroecológicas seguras e justas ambientalmente, com 
adoção de práticas sustentáveis tais como programas de reciclagem, uso eficiente de energia e água, bem como a redução de resíduos sólidos gerados (JANG et al., 2011; MARTINS, 2014).

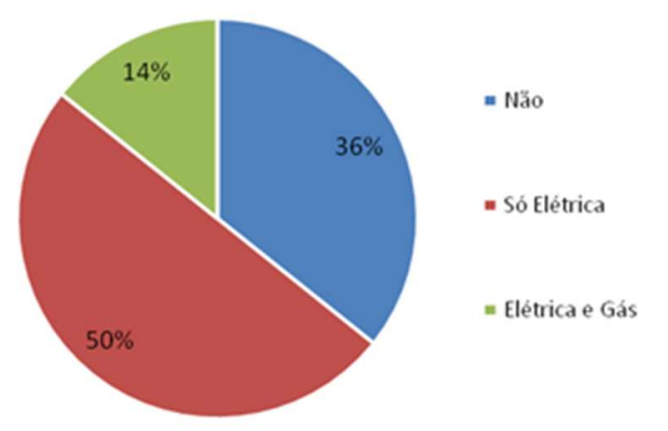

Gráfico 4: Uso de Fonte Alternativa de Energia.

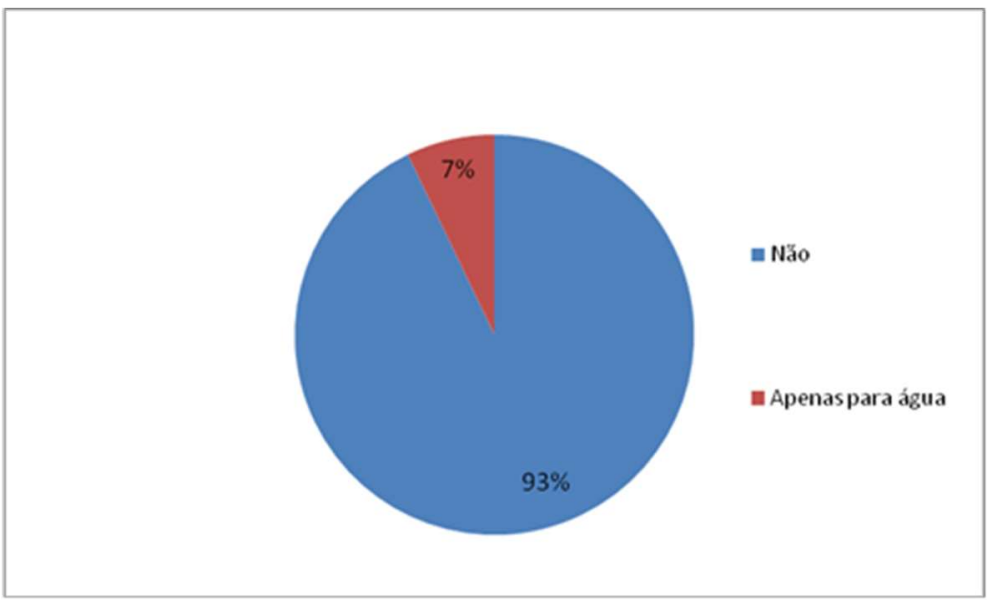

Gráfico 5: Programa sobre Desperdício de Água e Energia.

No que se refere à responsabilidade pelo planejamento dos cardápios, a maioria (64\%) das UANs responsabiliza os próprios nutricionistas pelo planejamento dos cardápios, enquanto $36 \%$ deixam que a matriz da empresa a que são filiadas as unidades determine o cardápio, fato esse preocupante, já que a matriz adota cardápios genéricos, não levando em consideração a especificidade de cada região onde está instalada a UAN. A responsabilidade atribuída ao Nutricionista da UAN é ideal, uma vez que o profissional conhece o perfil regional dos alimentos e dos comensais, auxiliando de maneira eficiente e eficaz na oferta de nutrientes ao público-alvo.

Em se tratando de Treinamento sobre Sustentabilidade Ambiental para manipuladores de alimentos, somente 04 unidades (29\%) o fazem, em desfavor da maioria (71\%) que não o faz, fato preocupante já que os manipuladores são os diretamente responsáveis pelo que é produzido e consumido na UAN, sendo necessário investir na qualificação desses profissionais.

Outro aspecto analisado durante a pesquisa referiu-se ao gerenciamento do descarte de resíduos orgânicos. Observando o Gráfico 6 percebe-se que em 50\% das unidades esses itens são separados e transportados pela empresa de coleta do poder municipal; em $29 \%$ das unidades não há separação e a coleta também é realizada por empresa pública municipal; os demais $21 \%$ são distribuídos igualmente entre 
unidades que separam o resíduo e o transporte acontece por empresa terceirizada; separam o resíduo e este segue para compostagem; ou adotam outra forma de gerenciamento diferente da apresentada.

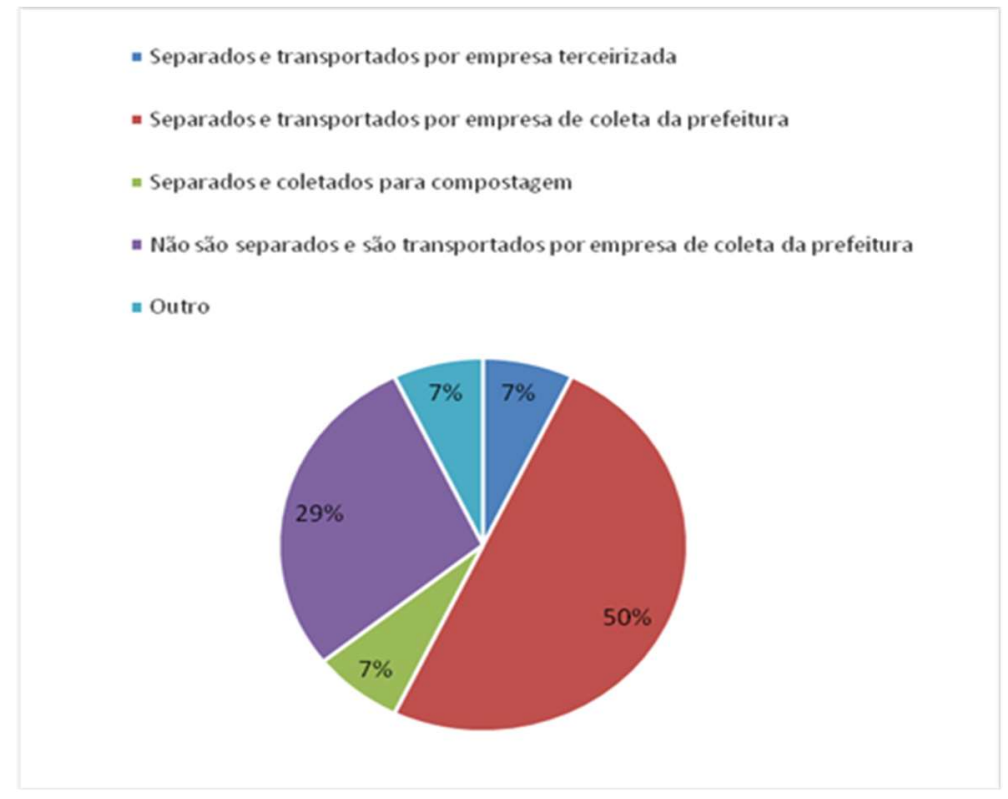

Gráfico 6: Destino dos Resíduos Orgânicos.

Essa preocupação com o destino dos resíduos orgânicos é uma das principais preocupações da sociedade, pois o crescimento populacional, o desenvolvimento industrial e a urbanização acelerada, atrelados à postura individualista da sociedade, contribuem para o uso abusivo dos recursos naturais e para a geração de resíduos que depois são devolvidos ao meio ambiente de forma inadequada (MAZZER et al., 2004).

O Gráfico 7 apresenta os resultados referentes ao destino dos resíduos recicláveis gerados nas UANs. 57\% dos resíduos sequer são separados, mas são transportados pela empresa de coleta das prefeituras locais; $29 \%$ separam os recicláveis, os quais também são coletados pela prefeitura; $7 \%$ das unidades separam os resíduos recicláveis e os entrega a catadores desse tipo de material; e outros $7 \%$ adotam medidas diferentes das mencionadas.

A reciclagem consiste em uma prática sustentável que deve ser fomentada nas UANs tendo em vista ser um processo de reaproveitamento dos resíduos sólidos no qual seus componentes são separados, transformados e recuperados, envolvendo economia de matérias-primas e energia, combate ao desperdício, redução da poluição ambiental e valorização dos resíduos, com mudança de concepção em relação aos mesmos.

A pesquisa também buscou identificar o destino do óleo de fritura gerado nas UANs. Conforme apresentado no Gráfico 8, em 50\% das unidades o óleo é recolhido pela empresa de coleta municipal; outras $21 \%$ das unidades não realizam qualquer descarte, ou seja, jogam-no diretamente nas pias; e em $29 \%$ das unidades os resíduos são transportados por empresas terceirizadas que, sustentavelmente, convertem-no em biocombustíveis e sabão de limpeza. 


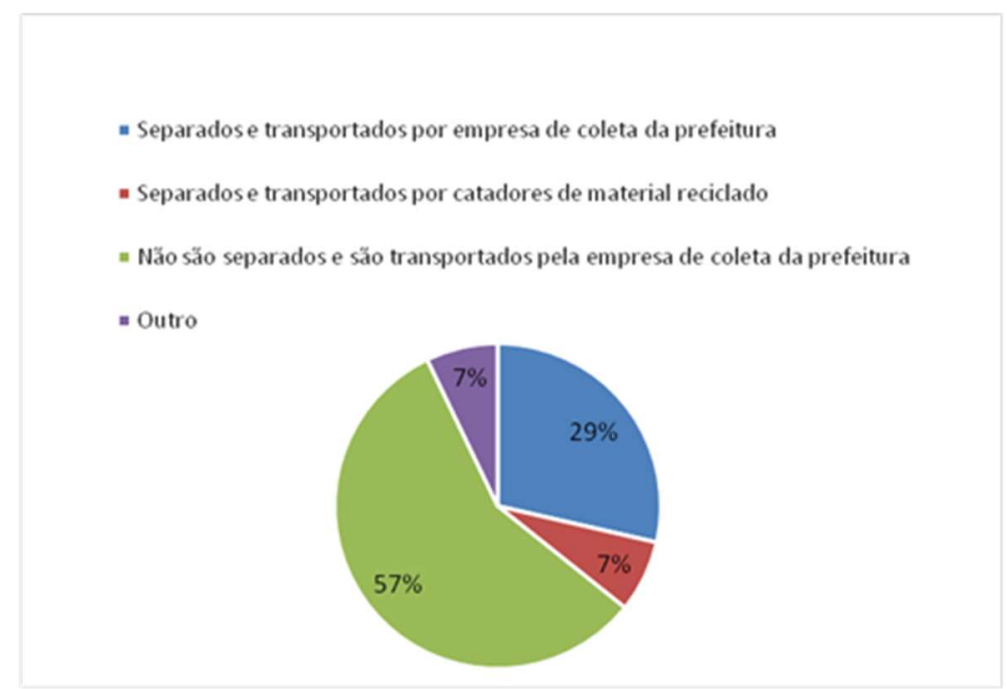

Gráfico 7: Destino dos Resíduos Recicláveis.

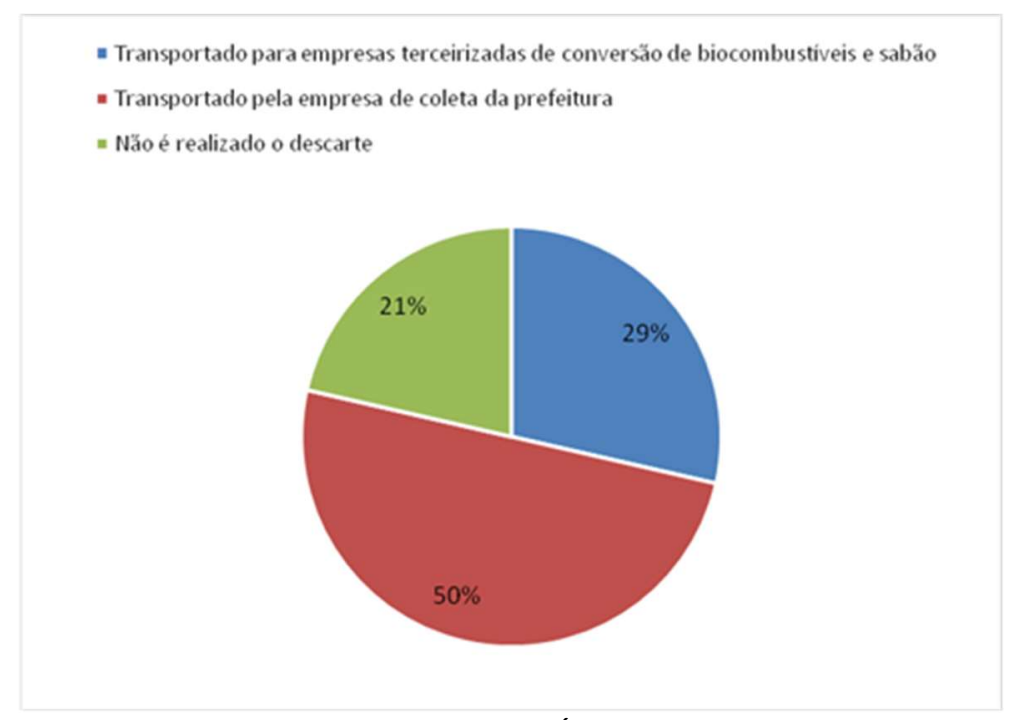

Gráfico 8: Destino do Óleo de Frituras

O óleo de fritura, depois de sustentavelmente aproveitado, pode ser utilizado como matéria-prima para produção de resina para tintas, sabão, detergente, amaciante, sabonete, glicerina, ração para animais, biodiesel, lubrificante para carros e máquinas agrícolas e outros. A crescente preocupação em relação ao meio ambiente e o aumento do uso do óleo de cozinha, frequentemente utilizado em frituras, sem falar no mal que o 'excesso' pode causar ao organismo, também produz dano ao meio ambiente se jogado pelo ralo da pia, pois provoca o entupimento das tubulações nas redes de esgoto, aumentando em até $45 \%$ os seus custos de tratamento, fato este preocupante entre as unidades que nada fazem com esse resíduo.

\section{CONCLUSÕES}

A análise das práticas sustentáveis adotadas pelas Unidades de Alimentação e Nutrição dos hospitais públicos em Sergipe permitiu concluir que a gestão dessas unidades, ainda que incipientemente, apresenta consciência ambiental, pois algumas iniciativas já foram adotadas, apesar de ainda haver muito por se fazer. A implementação de ações de sustentabilidade em UAN exige que o nutricionista responsável, no papel de gestor, se envolva, influencie e apoie a implementação e o desenvolvimento dessas práticas, as quais podem 
repercutir positivamente no aspecto financeiro, tornando-se a sustentabilidade uma importante estratégia de gestão econômico, ambiental e social.

É necessário maior controle com a geração e destino dos resíduos orgânicos, recicláveis e dos óleos provenientes de frituras, além da necessidade de monitoramento dos restos e sobras alimentares. Esse maior controle, para evitar a alta produção de resíduos orgânicos, pode acontecer através da adoção de medidas que minimizem a geração, exigindo que o responsável pela gestão da UAN se conscientize ainda mais da importância do seu papel perante a sustentabilidade, implantando programas de sensibilização, sistemas de qualidade e capacitação dos funcionários envolvidos, para que as práticas de redução, reutilização e reciclagem de resíduos passem a fazer parte diária da UAN. Portanto, as práticas sustentáveis a serem adotadas para o futuro devem se basear na conservação e uso consciente do solo, da água e de energia para garantir a produção das refeições.

\section{REFERÊNCIAS}

ABREU, E. S.; SPINELLI, M. G. N.; ZANARDI, A. M. P.. Gestão de Unidades de Alimentação e Nutrição: Um modo de fazer. Metha Ltda, 2011.

AGUIAR, J. A.; CALIL, R. M.. Tempo e temperatura de pratos quentes servidos no serviço de alimentação escolar em Cajamar. Rev. Nutrição Brasil, São Paulo, v.2, p.134-139. 2003.

ARSDEL, W.; COPLEY, M. J.; OLSON, R. L.. Quality and stability of frozen foods time temperature tolerance and its significance. 1969.

BELLEN, H. M. V.. Desenvolvimento sustentável: uma descrição das principais ferramentas de avaliação. Revista Ambiente \& Sociedade, Campinas, n.1, v.7, 2004.

BERNARDES, J. A.; FERREIRA, F. P. M.. Sociedade e natureza. In: CUNHA, S. B.; GUERRA, A. J. T.. A questão ambiental: diferentes abordagens. Rio de Janeiro: Bertrand Brasil, 2003. p.15-42.

BOSSEL, H.. Indicators for Sustainable Development: Theory, Method, Applications: A report to the Balaton Group. Winnipeg: IISD, 1999.

BRASIL. Resolução Lei n.12.305: Institui a Política Nacional de Resíduos Sólidos. Brasília: Agência Nacional de Vigilância Sanitária, 2010.

BROWN, L. R.. ECO-ECONOMIA Construindo uma Economia para a Terra. Salvador: UMA. 2003.

CASTRO, N. J.. A importância das Fontes Alternativas e Renováveis na Evolução da Matriz Elétrica Brasileira. 2009.

CAMARGO, A. L. B.. Desenvolvimento Sustentável: Dimensões e Desafios. 3 ed. Campinas: Papirus, 2007.

CAVALCANTI, C.. Desenvolvimento e Natureza: estudos para uma sociedade sustentável. São Paulo: Cortez, 2003.

COLARES, L. G. T.; FREITAS, C. M.. Processo de trabalho e saúde de trabalhadores de uma unidade de alimentação e nutrição: entre a prescrição e o real do trabalho. Cad. Saúde Pública, Rio de Janeiro, v.23, p.3011- 3020, 2007.

COSTA, S. L.. Gestão Integrada de Resíduos Sólidos Urbanos: Aspectos Jurídicos e Ambientais. Aracaju: Evocati, 2011.

COSTELLO, A.; ABBAS, M.. Managing the health effects of climate change: Lancet and University College London Institute for Global Health Commission. The Lancet, v.373, n.9676, p.1693-1733. 2009.

CUNHA, T.; STEDEFELDT, E.; ROSSO, V. V.. The role of theoretical food safety training on Brazilian food handlers' knowledge, attitude and practice. Food Control., v.43, p.167-174, 2014.

FEITOSA, F. R. S.. Indicadores de Sustentabilidade como Subsídio para a Prevenção da Infestação pelo Mosquito Aedes Aegypti no Município de Aracaju/SE. Dissertação (Mestrado em Desenvolvimento e Meio Ambiente) Universidade Federal de Sergipe, São Cristóvão, 2016.

FENNEMA, O.; POWRIE, W.; MARTH, E.. Low-temperature preservation of foods and living matter.1973.

FRANCO, J. L. A.; DRUMMOND, J. A.. O Cuidado da Natureza: A Fundação Brasileira para a Conservação da Natureza e a Experiência Conservacionista no Brasil: 1958-1992. Textos de história, v.17, n.1-2, p.145-149, 2009.

FRIEL, S.; DANGOUR, A. D.; GARNETT, T.; LOCK, K.; CHALABI, Z.; ROBERTS, I.; BUTLER, A.; BUTLER, C. D.; WAAGE, J.; MCMICHAEL, A. J.; HAINES, A.. Public health benefits of strategies to reduce greenhouse-gas emissions: food and agricultural. The Lancet, v.374, n.9706, p.2016-2025, 2009. DOI: http://doi.org/10.1016/S0140-6736(09)61753-0

GALISA, M. S.. Educação alimentar e nutricional: da teoria à prática. São Paulo: Roca, 2014.

GIL, A. C.. Métodos e Técnicas de Pesquisa Social. 6 ed. São Paulo: Atlas, 2010. 
JANG, Y. J.; KIMB, W. G.; BONN, M. A.. Generation Y consumers' selection attributes and behavioral intentions concerning green restaurants. International Journal Hospitality Management, n.30, p.803-811. 2011. DOI: http://doi.org/10.1016/j.ijhm.2010.12.012

JURAS, I. A. G. M.. Mecanismo de desenvolvimento limpo: fundamentos, histórico e estatística. Brasília: Câmara dos deputados, Consultoria legislativa, 2007.

LEAL, D.. Crescimento da alimentação fora do domicílio. Revista Segurança Alimentar e Nutricional, Campinas, v.17, n.1, p.123-132,2010.

LEFF, E.. Discursos sustentáveis. São Paulo: Cortez, 2010.

LIMA, P. V. P. S.; RODRUIGUES, M. I. V.. As políticas públicas e a sustentabilidade dos assentamentos de reforma agrária. In: Reforma Agrária em processo: quatro estudos empíricos, Concurso Josué de Castro. São Paulo: MDA, 2007.

MARTINS, A. M.. Sustentabilidade ambiental em unidades de alimentação e nutrição coletivas de Santa Catarina. Dissertação (Mestrado em Nutrição) - Universidade Federal de Santa Catarina, Florianópolis, 2015.

MARQUES, E. S.; COELHO, A. I. M.; HORTS, S.. Controle de sobra limpa no processo de produção de refeições em restaurantes. Revista Higiene Alimentar, São Paulo, v.22, n.160, p.20-24, 2008.

MAZZER, C. C.. Introdução à gestão ambiental de resíduos. Infarma, v.16, n.11-12, 2004.

PAGOTTO, H. Z.; ESPÍNDULA, L. G.; VITÓRIA, A. G.; MACHADO, M. C. M. M.; SÃO JOSÉ, J. F. B.. Nível de conhecimento, atitudes e práticas dos manipuladores de alimentos em serviços de alimentação. Demetra: alimentação, nutrição \& saúde, v.13, n.1, p.293-305, 2018.

PIRES, C. V.; LIMA, A.. Ecoaldeias: práticas de cuidado a nível global e local. Revista de Sociologia-Configurações, v.11, p.1-11, 2014. DOI: http://configuracoes.revues.org/1935

RABELO, N. M. L.; ALVES, T. C. U.. Avaliação do percentual de resto-ingestão e sobra alimentar em uma unidade de alimentação e nutrição institucional. Revista Brasileira de Tecnologia Agroindustrial, Ponta Grossa, v.10, n.1, p.20392052, 2016.

SCANDER NETO, W. J.. Síntese que organiza o olhar: uma proposta para construção e representação de indicadores de desenvolvimento sustentável e sua aplicação para os municípios fluminenses. Dissertação (Mestrado) - Escola Nacional de Ciências Estatísticas, Rio de Janeiro, 2006.

SOUSA, A. A.; GLÓRIA, M. S.; CARDOSO, T. S.. Aceitação de dietas em ambiente hospitalar. Rev. Nutr. Campinas, v.24, n.2, p.287-294, 2011. DOI: http://dx.doi.org/10.1590/S1415$\underline{52732011000200009}$

SOUZA, D. T. B.. Seleção de indicadores para gestão sustentável da Olericultura em Itabaiana/SE. Dissertação (Mestrado em Desenvolvimento e Meio Ambiente) Universidade Federal de Sergipe, São Cristóvão, 2008.

SOUZA, V. S. F.; SAMPAIO, C. A. C.. Em busca de uma racionalidade convergente ao ecodesenvolvimento: um estudo exploratório de projetos de turismo sustentável e de responsabilidade social empresarial. Revista de Administração Pública, Rio de Janeiro, v.40, n.3, 2006.

SRASBURGS, V. J.;VENZKE, J. G.; ALTMAYER, J.. Ações de redução de resíduos e de impactos ambientais em restaurantes universitários. In: CONGRESSO INTERNACIONAL DE TECNOLOGIAS PARA O MEIO AMBIENTE BENTO GONÇALVES/RS, 3. Anais. Brasília, 2012.

TEIXEIRA, S.; MILLET, Z.; CARVALHO, J.; BISCONTINI, T. M.. Administração Aplicada às Unidades de Alimentação e Nutrição. São Paulo: Atheneu, 2004

VAZ, C. S.. Restaurantes: Controlando custos e aumentando lucros. Brasília: LGE, 2006.

VEIROS, M. B.. Análise das condições de trabalho do nutricionista na atuação como promotor de saúde em uma unidade de alimentação e nutrição: um estudo de caso. Dissertação (Mestrado em Engenharia de Produção) Universidade Federal de Santa Catarina, Florianópolis, 2002

A CBPC - Companhia Brasileira de Produção Científica (CNPJ: 11.221.422/0001-03) detém os direitos materiais desta publicação. Os direitos referem-se à publicação do trabalho em qualquer parte do mundo, incluindo os direitos às renovaç̃os, expansões e disseminacõos da contribuicão, bem como outros direitos subsidiários. Todos os trabalhos publicados eletronicamente poderão posteriormente ser publicados em coletâneas impressas sob coordenação da Sustenere Publishing, da Companhia Brasileira de Produção Científica e seus parceiros autorizados. Os (as) autores (as) preservam os direitos autorais, mas não têm permissão para a publicação da contribuição em outro meio, impresso ou digital, em português ou em tradução. 